\title{
Cavitation in high-capacity tensiometers: effect of water reservoir surface roughness
}

Meghdad Bagheri MSC

PhD student, Department of Civil Engineering, University of Nottingham, Nottingham, UK (Orcid:0000-0002-9748-4165)

Mohammad Rezania PhD

Associate Professor, School of Engineering, University of Warwick,

Coventry, UK (corresponding author: m.rezania@warwick.ac.uk)

(Orcid:0000-0003-3851-2442)
Mohaddeseh Mousavi Nezhad PhD

Assistant Professor, School of Engineering, University of Warwick, Coventry, UK (Orcid:0000-0002-0625-439X)

High-capacity tensiometers (HCTs) are sensors made to measure negative pore water pressure (suction) directly. In this paper, a new approach is proposed to expand the range and duration of suction measurements for a newly designed HCT. A new technique is employed to reduce significantly the roughness of the diaphragm's surface on the water reservoir side in order to minimise the possibility of gas nuclei development and the subsequent early cavitation at the water-diaphragm interface. The procedures employed for the design, fabrication, saturation and calibration of the new tensiometers are explained in detail. Furthermore, the performance of the developed HCTs is examined based on a series of experiments carried out on a number of unsaturated clay specimens. An improvement in maximum sustainable suction in the range of $120-150 \%$ of their nominal capacity was obtained from different surface treatment methods. Moreover, the results show an improvement of up to $177 \%$ for the long-term stability of measurements, compared to the developed ordinary HCTs with untreated diaphragms.

\section{Introduction}

Difficulties in the measurement and control of soil suction in laboratory- and field-based experiments has led to the development of a number of techniques such as filter paper, psychrometer, thermal conductivity sensors, axis translation, pressure plate and tensiometers. Among these techniques, only the tensiometer is capable of directly measuring soil suction under normal atmospheric conditions. Standard tensiometers typically comprise a porous ceramic filter attached to a water-filled tube connected to a pressure measurement system. Up until the early 1990 s, ceramic filters of -1 bar air-entry value (AEV) were used for the fabrication of tensiometers, hence limiting their suction measurements to values up to $100 \mathrm{kPa}$ (Stannard, 1992). To enhance the range of suction measurements further, considerable efforts were made by Ridley and Burland (1993) at Imperial College for the development of a high-capacity tensiometer (HCT) capable of measuring suctions of up to $1.5 \mathrm{MPa}$. The HCT shares a similar structure with the standard tensiometer and is composed of a pressure measurement device, a water reservoir and a high$\mathrm{AEV}$ porous disc as the interface between the soil and the pressure measurement device. The main drawback of these transducers is the so-called cavitation at suctions lower than the AEV of their ceramic disc. HCTs have recently received significant interest in laboratory measurements of soil suction mainly due to their fast response time, accurate measurements and ease of transport and installation in geotechnical apparatuses (Lourenço et al., 2012). Furthermore, the modified version of HCTs have been successfully utilised in field measurements of low suctions (Mendes et al., 2008; Ridley and Burland, 1996; Ridley et al., 2003; Tarantino et al., 2016; Toll et al., 2011). The properties of some of the most notable HCTs, reported in the literature, are summarised in Table 1. Some of these developed HCTs have been reported to show suction measurement capacities of up to about $2 \mathrm{MPa}$. However, they have not been capable of continuously measuring high suctions $(>1 \mathrm{MPa})$ in the long term. Cunningham et al. (2003) reported the measurement of $850 \mathrm{kPa}$ suction for $8 \mathrm{~d}$ without cavitation occurring in the HCTs. The measurement of a suction value of $320 \mathrm{kPa}$ was also reported by Mancuso and Papa (2014) for a time period of about $10 \mathrm{~d}$. In essence, the lack of long-term proficiency of HCTs hinders their application for field monitoring or laboratory investigations where the continuous measurement of pore water pressure $\left(u_{\mathrm{w}}\right)$ variations is crucial. This paper presents the experimental procedures developed for the fabrication, saturation and calibration of a newly designed HCT. The novel techniques employed for improving the performance of the HCT in terms of maximum attainable suction $\left(s_{\max }\right)$ and maximum suction measurement duration $\left(t_{\max }\right)$ under high negative water pressures are explained in detail. In addition, the functionality of the improved HCT is examined based on a series of experiments performed on unsaturated clay specimens.

\section{Cavitation in HCTs}

In tensiometers, and in a very general definition, the fact that undissolved gas nuclei often appear in the corners of the water reservoir is called cavitation. The undissolved gas nuclei are typically found in the forms of entrapped air and water vapour in the crevices at the boundary between the liquid and the solid wall of the water reservoir or between the liquid and small particles suspended in the liquid. When a tensiometer is placed in contact with an unsaturated soil, the water pressure inside the reservoir is dropped progressively, resulting in the entrapped gas bubbles being pulled out from the crevice and forming a free cavity. Air diffusion into the cavity will also cause the volume expansion of the trapped gas and can result in the formation of free cavities 
Table 1. Properties of the developed HCTs

\begin{tabular}{|c|c|c|c|c|c|}
\hline Authors & $\begin{array}{l}\text { AEV: } \\
\text { MPa }\end{array}$ & Pressure measurement system & $\begin{array}{l}\text { Size of water } \\
\text { reservoir: } \mathrm{mm}^{3}\end{array}$ & $\begin{array}{l}\text { Max. measured } \\
\text { suction: } \mathrm{kPa}\end{array}$ & $\begin{array}{l}\text { Max. measurement } \\
\text { duration: } \min \end{array}$ \\
\hline $\begin{array}{l}\text { Ridley and Burland } \\
\text { (1993) }\end{array}$ & $1 \cdot 5$ & Entran EPX (3.5 MPa) & & 1370 & 1440 at $700 \mathrm{kPa}$ \\
\hline $\begin{array}{l}\text { Ridley and Burland } \\
\text { (1995) }\end{array}$ & $1 \cdot 5$ & Strain-gauged diaphragm (4 MPa) & 4 & $1800^{a}$ & \\
\hline $\begin{array}{l}\text { Guan and Fredlund } \\
\text { (1997) }\end{array}$ & $1 \cdot 5$ & Brand not given (1.5 MPa) & $\begin{array}{l}\text { Min. }=3 \cdot 85 \\
\text { Max. }=19 \cdot 24\end{array}$ & $1200-1250$ & 4320 at $700 \mathrm{kPa}$ \\
\hline \multirow{3}{*}{$\begin{array}{l}\text { Ridley and Burland } \\
\text { (1999) }\end{array}$} & $0 \cdot 1$ & \multirow[t]{3}{*}{ Strain-gauged diaphragm } & & 164 & \\
\hline & 0.5 & & & 740 & \\
\hline & $1 \cdot 5$ & & & 1800 & \\
\hline Sjoblom (2000) & $1 \cdot 5$ & Strain-gauged diaphragm & & 2200 & \\
\hline $\begin{array}{l}\text { Meilani et al. } \\
(2002)\end{array}$ & $0 \cdot 5$ & Druck PDCR 81 (1.5 MPa) & & 495 & \\
\hline $\begin{array}{l}\text { Mahler et al. } \\
(2002)\end{array}$ & 0.5 & Ashcroft K8 & & 350 & \\
\hline $\begin{array}{l}\text { Tarantino and } \\
\text { Mongiovi (2002) }\end{array}$ & $1 \cdot 5$ & Strain-gauged diaphragm (4 MPa) & $<4 \cdot 5$ & 2063 & 22540 at $1000 \mathrm{kPa}$ \\
\hline \multirow{2}{*}{$\begin{array}{l}\text { Take and Bolton } \\
(2003)\end{array}$} & $0 \cdot 1$ & \multirow{2}{*}{$\begin{array}{l}\text { Druck PDCR } 81(1.5 \mathrm{MPa}) \text { and Entran EPB } \\
(0.7 \mathrm{MPa})\end{array}$} & \multirow{2}{*}{$\sim 3$} & \multirow{2}{*}{$\begin{array}{r}\sim 130 \\
530\end{array}$} & \\
\hline & $\begin{array}{l}0.3 \\
1.5\end{array}$ & & & & \\
\hline Toker et al. (2004) & 1.5 & Data Inst. Inc. AB-HP 200 & & 1300 & \\
\hline Chiu et al. (2005) & 0.5 & Druck PDCR 81 (0.7 MPa) & & 472 & $\sim 18000$ at $110 \mathrm{kPa}$ \\
\hline Mantho (2005) & 1.5 & Strain-gauged diaphragm & & 1573 & \\
\hline $\begin{array}{l}\text { Lourenço et al. } \\
\text { (2006) }\end{array}$ & $1 \cdot 5$ & $\begin{array}{l}\text { Ceramic transducer by Wykeham Farrance } \\
(1.0 \mathrm{MPa})\end{array}$ & 5 & 1231 & \\
\hline He et al. (2006) & 0.5 & Entran EPX-10I-250A (3.5 MPa) & 2 & 550 & \\
\hline \multirow{2}{*}{$\begin{array}{l}\text { Mahler and Diene } \\
(2007)\end{array}$} & \multirow{2}{*}{$\begin{array}{l}0.5 \\
1 \cdot 5\end{array}$} & Entran EPXO (0.5 MPa) & \multirow[t]{2}{*}{$5-112$} & 800 & \\
\hline & & $\begin{array}{l}\text { Entran EPX (1.5 MPa) } \\
\text { Ashcroft }(0.5-1.5 \mathrm{MPa})\end{array}$ & & 1465 & \\
\hline $\begin{array}{l}\text { Jotisankasa et al. } \\
\text { (2007) }\end{array}$ & 0.5 & Brand not given & 60 & 350 & \\
\hline $\begin{array}{l}\text { Lourenço et al. } \\
\text { (2008) }\end{array}$ & $1 \cdot 5$ & $\begin{array}{l}\text { Ceramic transducer by Wykeham Farrance } \\
(1.0 \mathrm{MPa})\end{array}$ & 5 & 2087 & \\
\hline Cui et al. (2008) & $1 \cdot 5$ & Strain-gauged diaphragm & & & $\begin{array}{l}\sim 30000 \text { at } \\
20-160 \mathrm{kPa}\end{array}$ \\
\hline Rojas et al. (2008) & 0.5 & Strain-gauged diaphragm & 3 & 450 & \multirow[t]{3}{*}{$\sim 8400$ at $350 \mathrm{kPa}$} \\
\hline \multirow{2}{*}{$\begin{array}{l}\text { Mendes and Buzzi } \\
\text { (2013) }\end{array}$} & 0.5 & 147F Precision Measurement Company & 1100 & 920 & \\
\hline & $1 \cdot 5$ & (3.5 MPa) and Entran EPX (3.5 MPa) & & 1520 & \\
\hline $\begin{array}{l}\text { Mancuso and Papa } \\
\text { (2014) }\end{array}$ & 0.5 & Strain-gauged diaphragm & 3 & & $\sim 14400$ at $320 \mathrm{kPa}$ \\
\hline $\begin{array}{l}\text { Li and Zhang } \\
(2014)\end{array}$ & $1 \cdot 5$ & EPXO pressure transducer & & 1100 & \\
\hline \multirow{2}{*}{$\begin{array}{l}\text { Mendes et al. } \\
(2016)\end{array}$} & 0.7 & Ceramic flush diaphragm transducer (2.0 MPa) & \multirow[t]{2}{*}{40 and 430} & $\sim 700$ & \\
\hline & $1 \cdot 5$ & $\begin{array}{l}\text { Ceramic cavity diaphragm transducer }(2.0 \mathrm{MPa}) \\
\text { Stainless steel flush diaphragm transducer } \\
(2.0 \mathrm{MPa})\end{array}$ & & $\sim 2100$ & \\
\hline $\begin{array}{l}\text { Wijaya and Leong } \\
\text { (2016) }\end{array}$ & 0.5 & Entran EPX-10I-250A (3.5 MPa) & $<19$ & 1300 & \\
\hline $\begin{array}{l}\text { Tarantino et al. } \\
\text { (2016) }\end{array}$ & $0 \cdot 8$ & Strain-gauged diaphragm & & 800 & $\sim 18720$ at $800 \mathrm{kPa}$ \\
\hline
\end{tabular}

${ }^{a}$ A maximum value of $2900 \mathrm{kPa}$ was measured by Tarantino and Mongiovi (2002) using this HCT

(Marinho et al., 2008). Another mechanism for cavitation can be the air diffusion from the air-saturated water in the soil to the deaired water in the porous disc and the water reservoir of the tensiometer (Ridley et al., 2003). Therefore, it is reasonable to conclude that in HCTs, cavitation can occur in both the porous ceramic and the water reservoir. However, it is not yet clear which cavitation mechanism is predominant and whether the cavitation initiates in the porous ceramic or water reservoir.
Ridley et al. (2003) stated that if a tensiometer cavitates at a suction close to the AEV of its ceramic filter, the cavitation mechanism can be explained by air breaking into the ceramic filter from the atmosphere. On the other hand, cavitation occurrence at suctions below the AEV of the ceramic disc can be attributed to the release of trapped gas bubbles from the small crevices on the walls of the water reservoir (Ridley, 1993; Ridley et al., 2003; Take, 2003). To reduce the number of crevices and 
possible nucleation sites, it is necessary for the surfaces, which are in contact with water, to be as smooth as possible (Marinho and Chandler, 1994). Ensuring clean surfaces within the measurement system and using clean and pure water (Henderson and Speedy, 1980) are the other important factors in minimising cavitation occurrence during suction measurements. The reduction in the number of potential cavitation nuclei can also be achieved by reducing the amount of free water in the water reservoir of the instrument (Marinho and Pinto, 1997; Ridley and Burland, 1993; Tarantino and Mongiovi, 2002). From the high-speed photography analysis carried out to capture the cavitation mechanism in HCTs, Mendes and Buzzi (2013) observed the simultaneous growth of air bubbles from the water reservoir wall on the pressure sensor side and the ceramic wall during cavitation, suggesting the initiation of cavitation in both reservoir and ceramic filter. According to Mendes and Buzzi (2013), cavitation occurrs when air bubbles (developed either in the ceramic or on the reservoir wall) reach the water reservoir. This means that the maximum suction can still be sustained even if some small air bubbles are formed within the porous ceramic. In other words, the small air bubbles, developed in either the ceramic filter or reservoir, can only collate to create an air cavity inside the water reservoir, as it has a larger volume than the ceramic filter (Lourenço, 2008). Therefore, considering a smallsized reservoir with minimised numbers of crevices on its walls can significantly contribute to measurement of high suctions.

\section{New design}

A total of 12 tensiometers were fabricated at the University of Warwick. Figure 1 presents the schematic sketch of the Warwick tensiometer (WT) and its components. The new tensiometer has retained the main features of the tensiometer developed at the University of Trento (Tarantino and Mongiovi, 2002). Modifications were introduced to the size of the water reservoir and the method used for smoothening the diaphragm's surface on the side that is in contact with water with the aim to minimise the presence of entrapped air bubbles. The tensiometer body was machined in the milling machine from one single cylindrical piece of AISI 304 stainless steel. The WT's diaphragm is $0.4 \mathrm{~mm}$ thick and has an internal diameter of $7 \mathrm{~mm}$. The water reservoir has a diameter of $6 \mathrm{~mm}$ and a depth of $0.1 \mathrm{~mm}$. In comparison to the

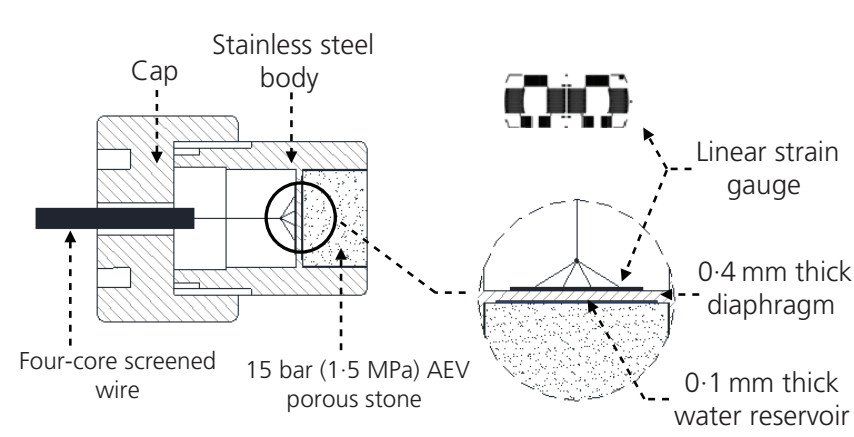

Figure 1. Schematic diagram of the tensiometer and its components
Trento tensiometer, the reservoir is smaller in diameter which results in $17.5 \%$ reduction of the free water volume in the reservoir. During the removal of the last $0 \cdot 1 \mathrm{~mm}$ of the diaphragm thickness, a refined milling pattern was considered in order to minimise the depth of the developed revolution ridges during machining. The surface roughness of the diaphragm on the water reservoir side was reduced using different metal-polishing and surface-coating techniques (explained in the next section of this paper).

The WTs benefit from a strain-gauged diaphragm as the pressure measurement system. A linear-type strain gauge was used, which is composed of radial and tangential strain gauges combined in a Wheatstone bridge to generate the highest sensitivity. Figure 2 presents a schematic diagram of the linear strain gauge and its internal circuit. The parameters $\varepsilon_{\mathrm{R}}$ and $\varepsilon_{\mathrm{T}}$ denote radial and tangential strains, respectively. The strain gauge was wired and bonded to the back of the diaphragm. Considering an output signal amplification (gain) of 500, the signal resolution was obtained as $0.3 \mu \mathrm{V}$ that gave a resolution of $0.23 \mathrm{kPa}$ to the instrument.

The WTs were also fitted with 1.5 MPa AEV porous ceramics, which were machined to the appropriate size and glued within the tensiometer's body. A gap of $0.05 \mathrm{~mm}$ was considered between the ceramic and the metal, and the adhesive was applied uniformly along the sides of the cylindrical ceramic. The AEV of the porous ceramics are typically considered as the nominal capacity of the tensiometers (Take and Bolton, 2003).

\section{Minimising diaphragm's surface roughness}

In theory, the face-milling (FM) method, used for machining the diaphragm, should produce very flat surfaces. However, the microscopic inspection of the finished surfaces indicated the existence of deep revolution marks (see Figure 6(a)), resulting from the motion of the cutter's end face over the metal surface. It was therefore essential to reduce the number and the depth of these revolution marks and provide a less rough surface with the minimum number of potential nucleation sites. To this end, a proper surface-polishing technique should be employed. Typically, conventional polishing tools and techniques such as silicon carbide (SiC) abrasive papers (SPs), polishing stones, diamond

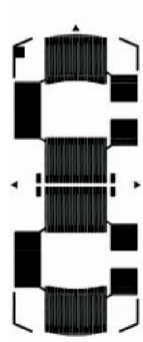

(a)

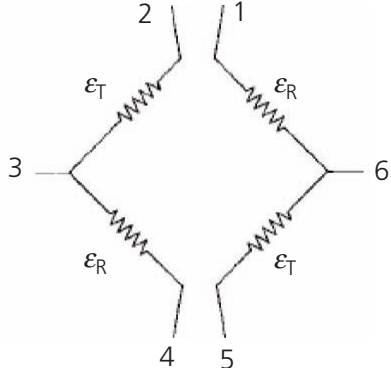

(b)
Figure 2. (a) Linear strain gauge and (b) internal circuit diagram 
paste, pneumatic abrading wheels or grinders and electrodischarge machining (EDM) are used for surface finishing (Tsai et al., 2008). These techniques are operationally straightforward and cost-efficient, but often involve human errors and the development of uneven polished surfaces due to the non-uniform force distribution during polishing. In order to improve the surface finish quality, non-conventional polishing techniques such as chemical polishing, electropolishing, abrasive flow polishing, abrasive jet machining, magnetic force polishing or a combination of mechanical and electropolishing methods have been proposed in the literature (Tsai et al., 2008; Wang et al., 1998; Yin and Shinmura, 2004). These methods, despite producing an improved surface finish, normally involve extended machining costs and time, occasional surface damage and environmental pollution (Tsai et al. 2008). The diversity of the available polishing methods makes it difficult to select one, given the feasibility and economic aspects of manufacturing HCTs. Therefore, in this work, a comparative study on the efficiency of the most common and cost-efficient metal-polishing methods - namely, SP and diamond paste abrasive (DP) - was carried out on dummy cylindrical stainless steel samples. Additionally, a new approach to minimise the diaphragm's surface roughness - namely, coating the surface with a thin microscopic layer of a hydrophilic material - is presented and discussed in the following subsections.

\section{Silicon carbide abrasive paper}

A common method for polishing metallic surfaces is the use of abrasive papers. The workpieces are normally polished by abrasive papers with increasing grit starting from a low grit number (coarse abrasives) to a high grit number (fine abrasives). In this study, two dummy samples were polished using SP of from number 400 to 1200 grit. It is commonly agreed that SP with increasing grit can produce smooth diaphragm surfaces. However, the microscopic inspection of the polished samples in this study (see Figure 6(b)) demonstrated that a significant amount of scratch marks was developed on the polished surfaces, which could potentially lead to the development of a considerable number of nucleation sites.

\section{Diamond paste abrasive}

In another attempt to obtain a smooth surface finish, two dummy samples were polished in the milling machine using DP. The samples were polished using DP with decreasing grades - that is,
$14,8,6,3,1$ and $0 \cdot 1 \mu \mathrm{m}$. This method is generally accepted to produce an improved surface finish in comparison to the SP-polishing technique (see Figure 6(c)).

\section{Coating diaphragms with hydrophilic materials}

According to Jones et al. (1999), the amount of air trapped in the crevices of the water reservoir depends on the geometry of the crevice as well as the advancing contact angle $\left(\theta_{\mathrm{a}}\right)$ of the liquid. The more a surface is hydrophobic (water repelling), the more is the possibility of air being trapped in its crevices due to the development of a higher $\theta_{\mathrm{a}}$ at the solid-liquid interface. Conversely, the development of a lower $\theta_{\mathrm{a}}$ at the solid-liquid interface of a less hydrophobic surface minimises the possibility of air entrapment in its crevices (Figure 3).

There are two common methods for enhancing the hydrophilicity of surfaces: $(a)$ deposition of a microscopic layer of a material more hydrophilic than the substrate and $(b)$ modification of the chemistry of the substrate using, for example, plasma or X-ray treatments (Drelich et al., 2011). In order to avoid the complexities associated with the latter method, in this study, the former method was applied for producing a smooth and waterattracting surface for the diaphragm inner walls. The deposition of a microscopic layer of a hydrophilic material, in most cases, can significantly reduce the surface roughness by filling the existing crevices on the substrate surface and, hence, decreasing porosities. An antifog (AF) agent, Triton X-100 surfactant and titanium dioxide $\left(\mathrm{TiO}_{2}\right)$ materials were chosen to coat the samples. Several techniques including ink-jet printing, spin coating and sputtering are often used for the deposition of films of nanoparticles on substrates (Drelich et al., 2011). Among these, the spin coating technique was found to be a more suitable method for coating the tensiometer diaphragms in the laboratory.

\section{Antifog agent}

AF agents are hydrophilic materials used to prevent fog formation on the surfaces of optical devices such as eyeglasses and goggles. As explained by Chevallier et al. (2011), the main concern in using highly hydrophilic AF coatings are that $(a)$ their solubility in water which can significantly affect their long-term functionality and $(b)$ their occasional poor adhesion to the substrates which is a function of physical interaction between the two materials. In recently developed AF agents, these problems

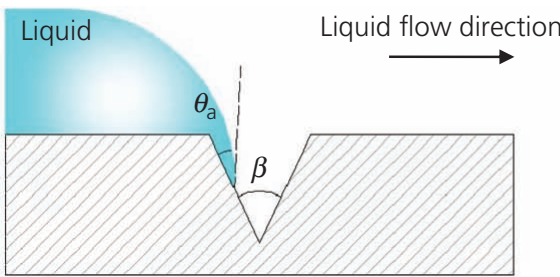

(a)

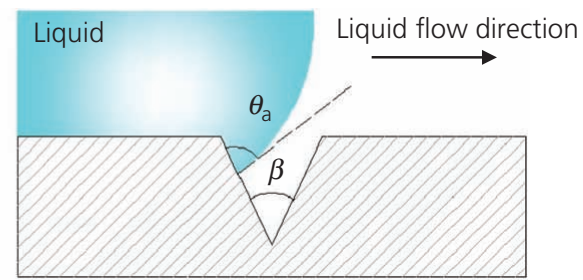

(b)

Figure 3. Effect of liquid advancing contact angle on air entrapment in a crevice: (a) less hydrophobic surface, low liquid contact angle and less entrapped air; (b) more hydrophobic surface, high liquid contact angle and more entrapped air (after Jones et al. (1999)) 
have been addressed by using cross-linking agents in the composition formulae (for further information, see Chevallier et al. (2011)).

A microscopic layer of the AF agent was uniformly spread over the surface of the DP-polished samples using the spin coating method. The surface was then left for curing under vacuum at $95^{\circ} \mathrm{C}$ for a time duration of $6 \mathrm{~h}$. The coated sample was then aged in deionised water for $24 \mathrm{~h}$ and under constant room temperature, then dried under ambient conditions. The thickness of the film was measured using profilometery (explained in the next section) and found to be on the order of $4 \mu \mathrm{m}$, which was thick enough to fill the valleys on the sample surface.

\section{Triton X-100 surfactant}

Triton X-100 (or octylphenol ethoxylate) is a non-ionic surfactant with excellent wetting characteristics. Similar to the AF agent, the water-solubility characteristic of Triton is considered as its main drawback for being used in coating the tensiometer's diaphragm. However, a microscopic layer of this material is believed to develop relatively strong bonding with the substrate and, hence, remain undissolved for a longer period of time (Chevallier et al., 2011). Similar to AF, the spin coating method was used for the deposition of Triton particles on the samples. The samples were then treated in a vacuum furnace under $240^{\circ} \mathrm{C}$ for $12 \mathrm{~h}$ in order to improve the bonding of the coating with the substrate.

\section{Titanium dioxide}

Titanium dioxide nanoparticles have been widely used in epoxy coatings to improve chemical resistance, corrosion resistance and the hydrophilicity of stainless steel substrates, given their high specific area and strong bonding properties to the metallic substrates (Conradi and Kocijan, 2016; Ohkoa et al., 2001; Yu et al., 2003). A thin film of this coating material was deposited on the DP-polished stainless steel samples using the spin coating method. The samples were then treated in a vacuum furnace under $300^{\circ} \mathrm{C}$ for $16 \mathrm{~h}$ to improve the stability of the coating. The microscopic layer of the titanium dioxide coating was also found to decrease the surface roughness by filling the valleys on the polished surfaces (see Figure 5(f)).

\section{Surface roughness analysis}

The analysis of the surface roughness obtained from polishing and coating methods was carried out using three distinctive methods, namely, surface metrology, microscopic inspection and contact angle measurement.

\section{Surface metrology}

The random irregularities developed during surface finishing processes, including milling, drilling and mechanical polishing, are known as surface texture or roughness (ISO/DIS 4287-1 (ISO, 1987)). Various parameters including roughness or arithmetic average deviation from the mean line $\left(R_{\mathrm{a}}\right)$, root mean square value of roughness $\left(R_{\mathrm{q}}\right)$, maximum peak of roughness $\left(R_{\mathrm{p}}\right)$, maximum valley of roughness $\left(R_{\mathrm{v}}\right)$ and maximum peak-to-valley height $\left(R_{\mathrm{t}}\right)$ can be used for the characterisation of surface texture (Hasegawa et al., 1976). Figure 4 presents a schematic definition of the surface texture parameters. For the measurement of these parameters, threedimensional (3D) surface metrology analysis was carried out on the dummy samples using a Bruker contour GT-K profiler.

Figure 5 presents the 3D surface topography images. The unevenness of the FM sample and presence of high peaks and deep valleys on the surface are clearly shown in Figure 5(a). These peaks and valleys are reduced on SP- and DP-polished samples (Figures 5(b) and 5(c)). The roughness is further decreased on the AF-coated, Triton-coated and titanium dioxide-coated samples (Figures 5(d)-5(f)), demonstrating the efficiency of the hydrophilic-coating method in achieving smooth surfaces. The surface texture parameters for some of the tested samples are given in Table 2. It must be noted that the surface texture parameters for the coated samples might have been slightly affected by the light refraction due to the transparency of the coating materials.

\section{Microscopic inspection}

A simple microscopic investigation using an optical microscope was carried out to evaluate the surface quality obtained from polishing and coating processes. Figure 6 presents the microscopic images of the finished surfaces. Also, present in Figure 6 are the microscopic images obtained from the profilometery analysis. It is clear from the images that the FM process creates deep revolution marks on the stainless steel surface, which are considered as potential nucleation sites (Figure 6(a)). The SP-polishing method significantly improved the surface finish quality, yet the development of shallow-depth revolution marks seems to be inevitable (Figure 6(b)). The number of the revolution marks was significantly reduced on the DP-polished sample, proving the suitability of this technique for achieving very smooth surfaces (Figure 6(c)). The microscopic images of the AF-coated sample (Figure 6(d)), Triton-coated sample (Figure 6(e)) and titanium dioxide-coated sample (Figure 6(f)) are slightly faded due to the viscosity and transparency of the coating materials, which cause light reflection. However, the microscopic layers of the hydrophilic coatings provide very smooth surfaces as can be seen in the profilometer images. It must be mentioned here

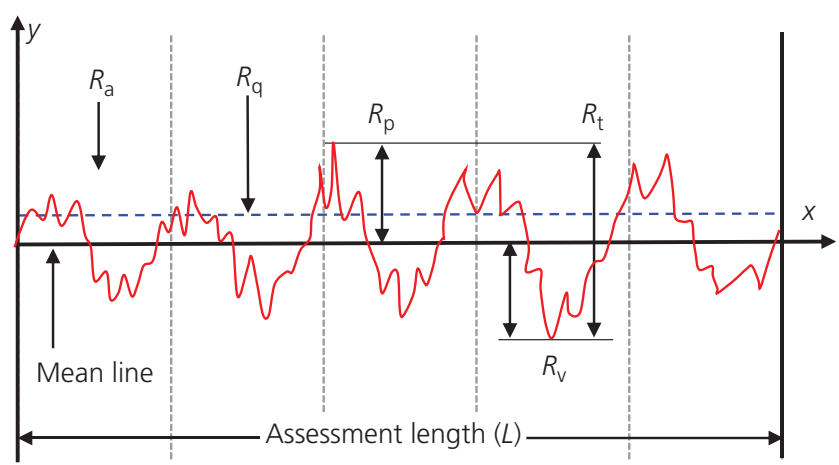

Figure 4. Surface texture parameters 
Geotechnical Research

Volume 5 Issue GR2
Cavitation in high-capacity tensiometers:

effect of water reservoir surface

roughness

Bagheri, Rezania and Mousavi Nezhad

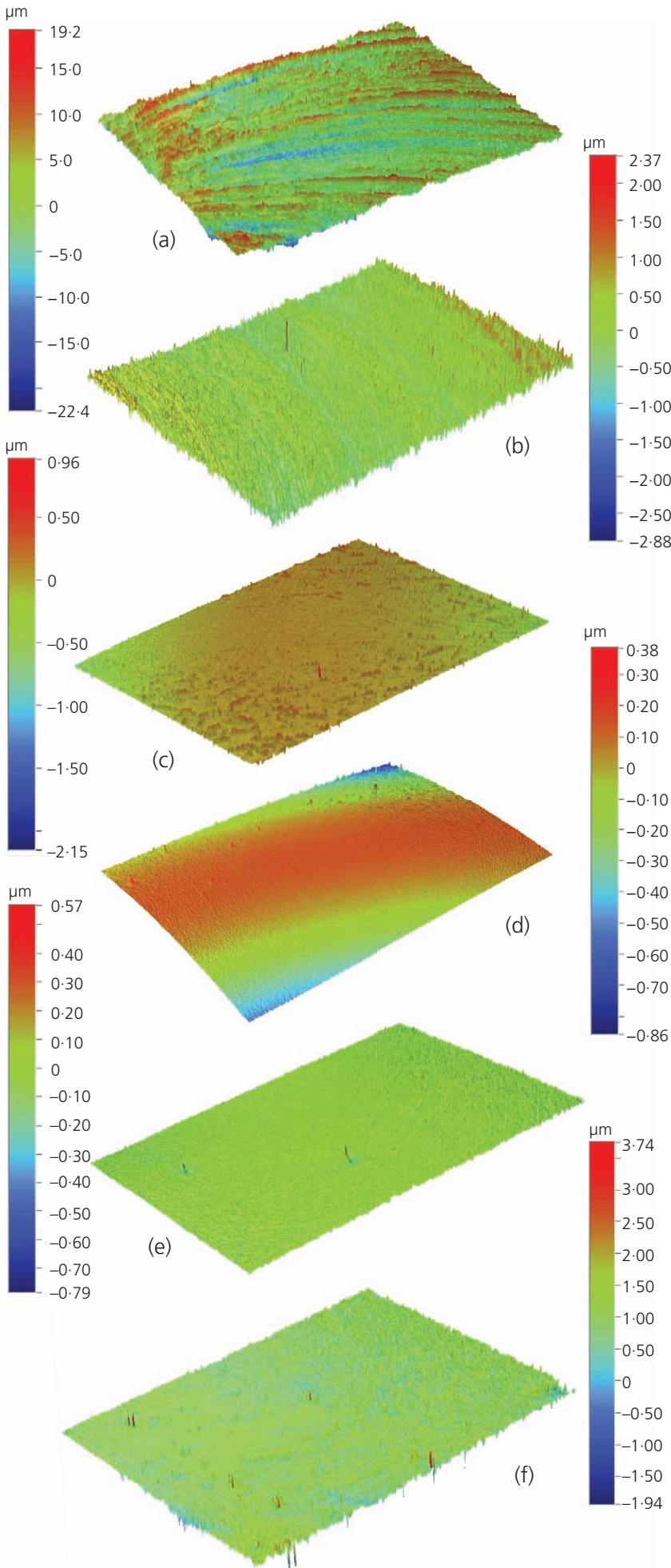

Figure 5. Three-dimensional surface metrology diagrams: (a) FM sample; (b) SP-polished sample; (c) DP-polished sample; (d) AF-coated sample; (e) Triton-coated sample; (f) titanium dioxide-coated sample
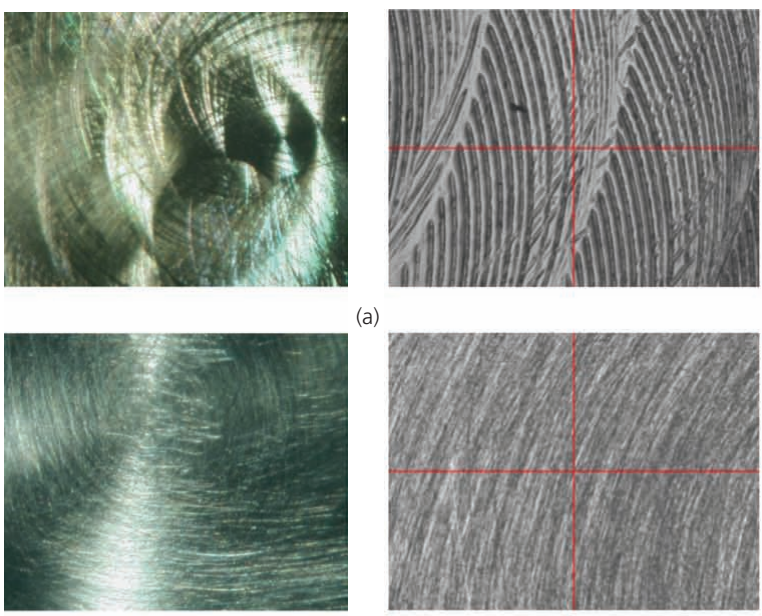

(b)
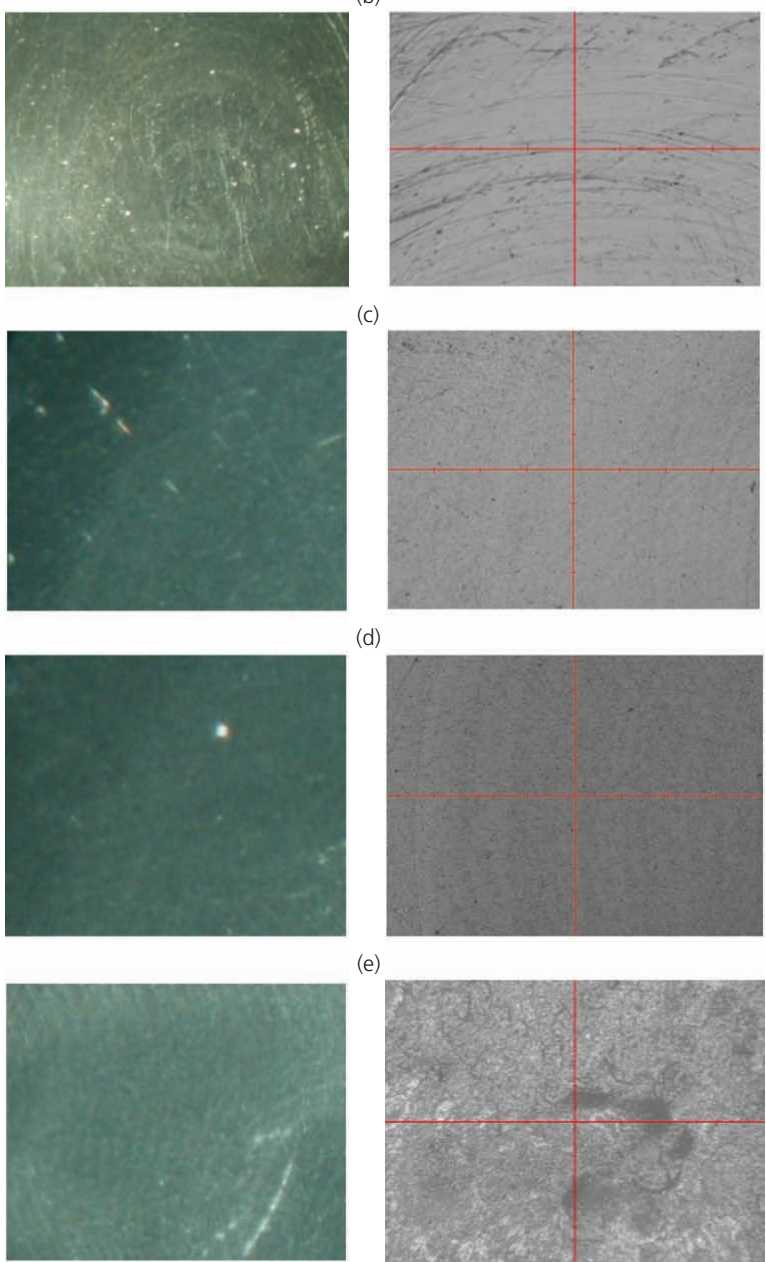

$(\mathrm{f})$

Figure 6. Microscopic view of the finished surfaces: (a) FM sample; (b) SP-polished sample; (c) DP-polished sample; (d) AFcoated sample; (e) Triton-coated sample; and (f) titanium dioxidecoated sample 
that the microscopic images of the titanium dioxide-coated sample present the distribution of the titanium nanoparticles on the surface. This should not be mistaken as the surface roughness of the sample (see Figure 5(f)).

\section{Contact angle}

Surface roughness can influence materials' properties such as friction and wettability. Wettability is characterised by contact angle $(\theta)$, which is defined as the developed angle at the solid-liquid interface of a liquid droplet deposited on a solid surface and in equilibrium with its vapour. The conventional range of contact angle for a well wetting surface is $0<\theta<90^{\circ}$. For materials with a contact angle range of $90^{\circ}<\theta<180^{\circ}$, the penetration (under gravity forces) of liquid into the rough surface asperities is restricted and gas bubbles can be entrapped in the existing crevices. This can result in the development of a discontinuous liquid-solid interface and an alternation of gas-liquid and solid-liquid interfaces (She and Sleep, 1998). In the modified classification of hydrophilic and hydrophobic surfaces presented by Drelich et al. (2011), a smooth solid surface is hydrophilic if $\theta \approx 0^{\circ}$, weakly hydrophilic if $0<\theta<\left(56-65^{\circ}\right)$, weakly hydrophobic if $\left(56-65^{\circ}\right)<\theta<90^{\circ}$ and hydrophobic if $90^{\circ}<\theta \leq 120^{\circ}$. Figure 7 schematically explains the role of hydrophilic coating in enhancing surface wettability and minimising the number of nucleation sites.

Contact angle measurements were carried out using a DataPhysics OCA 20 contact angle measurement apparatus. The common method of sessile drop (Drelich et al., 2011) was used to study wettability. The measurements for each sample were repeated three times, and representative apparent $\theta$ values were reported based on averaging the obtained values. Prior to measurements, all samples were cleaned with ethanol in an ultrasonic bath and then oven-dried at $80^{\circ} \mathrm{C}$. The whole measurement process was carried out under constant temperature of $21^{\circ} \mathrm{C}$ and ambient humidity. For each sample, water droplets of $1 \mu \mathrm{l}$ volume were placed at three different points over the surface area.

Figure 8 presents the results of contact angle measurements on the dummy samples. The measured contact angle on the FM sample $\left(\theta=74^{\circ}\right)$ was lower than that of the SP sample $\left(\theta=81^{\circ}\right)$, yet both were within the $\theta$ range associated with weakly hydrophobic materials. Similarly, the DP sample exhibited a larger contact angle $\left(\theta=87^{\circ}\right)$ than the SP sample with a $\theta$ value close to the boundary between hydrophobic and weakly hydrophobic materials. In fact, the improvement of surface roughness by polishing the samples using DP and SP methods decreased the hydrophilicity of the treated surfaces. The development of waterrepelling characteristics in the polished surfaces may, in turn, offset the improvement in cavitation occurrence, achieved by reducing surface roughness. The AF coating significantly improved the surface affinity to water and lowered the equilibrium apparent contact angle to $\theta=41^{\circ}$. Further improvement in hydrophilicity was achieved from the Tritoncoated sample with average contact angle of $\theta=34^{\circ}$. Similarly, the titanium dioxide-coated sample offered a contact angle of $\theta=$ $18^{\circ}$ representing significantly improved wetting characteristics.

\section{Experimental programme}

In order to examine the effect of diaphragm surface roughness on the performance of the HCTs, several HCT prototypes were manufactured with different surface treatment techniques applied to their diaphragms. Table 3 presents the properties of these manufactured HCTs. In the following subsections, the processes

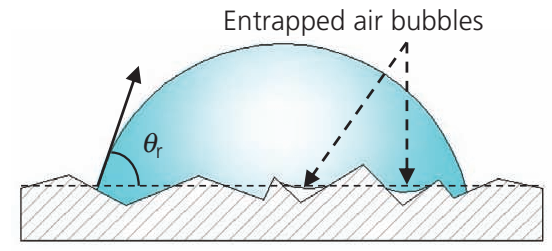

(a)

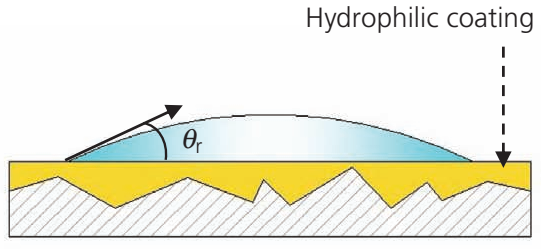

(b)

Figure 7. (a) Wettability of a rough surface (higher $\theta$ ); (b) enhanced wettability by coating the rough surface with a hydrophilic surfactant (lower $\theta$ )

Table 2. Examples of surface texture parameters obtained from 3D topography analysis on treated AISI 304 stainless steel samples

\begin{tabular}{lccccc} 
& \multicolumn{4}{c}{ Surface texture parameters } & \\
nymple & $R_{\mathrm{a}}$ & $R_{\mathrm{p}}$ & $R_{\mathrm{v}}$ & $R_{\mathrm{t}}$ & Surface treatment method \\
S1 & 7.811 & 18.379 & -21.285 & 39.664 & $\mathrm{FM}$ \\
S4 & 0.433 & 2.301 & -2.657 & 4.958 & SP polishing \\
S6 & 0.308 & 0.813 & -2.031 & 2.844 & DP polishing \\
S7 & 0.212 & 0.319 & -0.731 & 1.050 & Hydrophilic coating (antifog agent) \\
S10 & 0.145 & 0.285 & -0.281 & 0.566 & Hydrophilic coating (Triton X-100) \\
S11 & 0.163 & 2.742 & -1.938 & 4.680 & Hydrophilic coating (titanium dioxide)
\end{tabular}




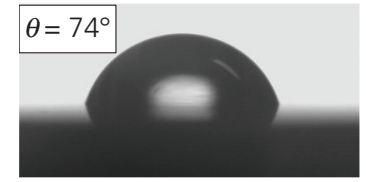

(a)

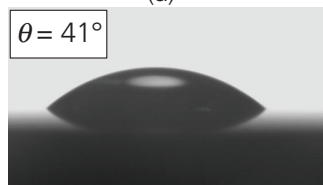

(d)

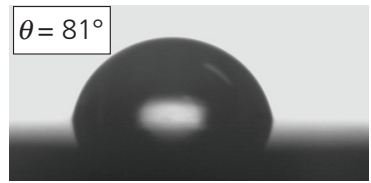

(b)

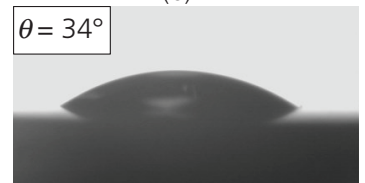

(e)

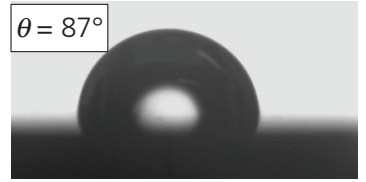

(c)

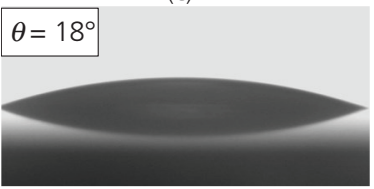

(f)

Figure 8. Measured contact angles: (a) FM surface $\left(\theta=74^{\circ}\right)$; (b) SP-polished surface $\left(\theta=81^{\circ}\right)$; (c) DP-polished surface $\left(\theta=87^{\circ}\right)$; (d) AF-coated surface $\left(\theta=41^{\circ}\right)$; (e) Triton-coated surface $\left(\theta=34^{\circ}\right)$; (f) titanium dioxide-coated surface $\left(\theta=18^{\circ}\right)$

Table 3. The manufactured HCTs

\begin{tabular}{ll}
\hline HCT & \multicolumn{1}{c}{ Diaphragm surface treatment } \\
\hline WT1, WT2 & FM \\
WT3, WT4 & SP polishing \\
WT5, WT6 & DP polishing \\
WT7, WT8 & Hydrophilic coating (antifog agent) \\
WT9, WT10 & Hydrophilic coating (Triton X-100) \\
WT11, WT12 & Hydrophilic coating (titanium dioxide)
\end{tabular}

of the saturation and calibration of the developed HCTs, together with the experimental programme followed for examination of their performances, are discussed in detail.

\section{Saturation and calibration}

The HCTs were saturated in a purpose-built saturation chamber following the procedure explained by Tarantino (2002). At the end of the saturation period, a simple examination was carried out to evaluate the success of the saturation process. First, a loading-unloading cycle was applied to the saturation chamber in steps of $100 \mathrm{kPa}$, and the HCT responses were monitored. Each loading (unloading) stage was maintained for $10 \mathrm{~min}$ so the sensors reach equilibrium with the applied pressure. All HCTs were found to respond immediately to the pressure change, and pressure equilibrium is established in less than $10 \mathrm{~min}$ for each loading (unloading) stage. According to Lourenço et al. (2006), the instantaneous response of the HCT to change in pressure during prepressurisation can be considered as an index for adequate saturation. Furthermore, as stated by Tarantino (2002), an adequately saturated tensiometer should reach pressure equilibrium within $1-2 \mathrm{~h}$ if immediately placed in free water by the end of saturation course; therefore, upon removing from the saturation chamber, the tensiometers were placed in free water, and the pressure changes were monitored. The residual pressure remaining in the sensors by the end of saturation course was found to vary between 39 and $12 \mathrm{kPa}$ (Figure 9). Equilibrium was achieved in $70-85 \mathrm{~min}$ for all tensiometers, indicating their adequate saturation.

In principle, tensiometers should be calibrated in negative pressure range. However, due to the difficulties in applying high negative pressures in laboratories, the calibration of tensiometers is normally carried out in a positive range, and a linear extrapolation to the calibration equation is developed for the pressures in negative range. Although the linear extrapolation method does not seem to be an ideal method, it has been widely accepted and justified by other HCT developers and/or users (e.g. Lourenço et al., 2008; Tarantino, 2002). In this study, the calibration of the tensiometers was performed in a positive range. A loading-unloading cycle was applied in steps of $100 \mathrm{kPa}$ and up to $1.5 \mathrm{MPa}$, and the corresponding voltage outputs were recorded. A linear trend for both loading and unloading cycles was obtained from the calibration plots. The calibration error, being the difference between the applied pressure and the measured value from the calibration equation, remained at a low range of $0 \cdot 25-0 \cdot 33 \%$.

\section{Determination of maximum sustainable suction $s_{\max }$}

A set of experiments was performed to examine the performance of the WTs in terms of $s_{\max }$. For this set of experiments, the ceramic filter was wiped and allowed to dry off at ambient temperature (free evaporation test). Figure 10 presents the results

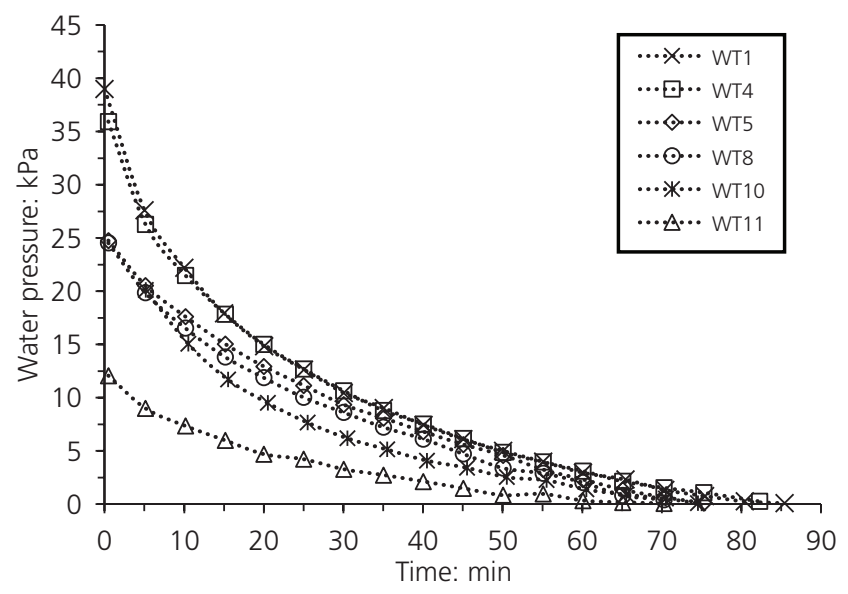

Figure 9. Residual pressure equilibrium by the end of saturation course 


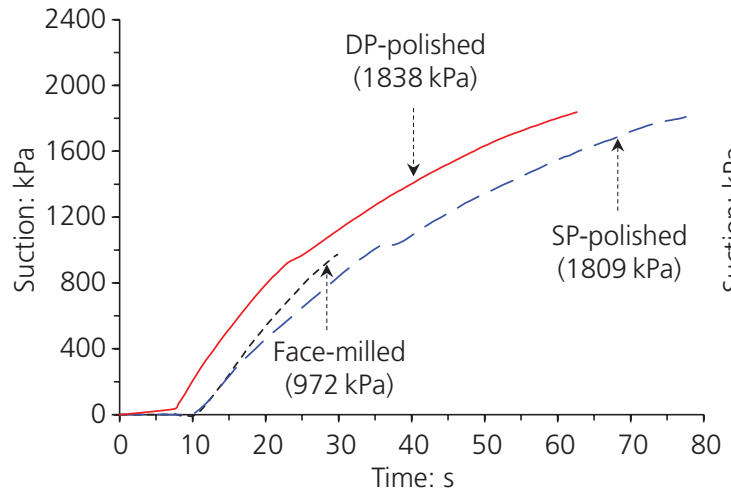

(a)

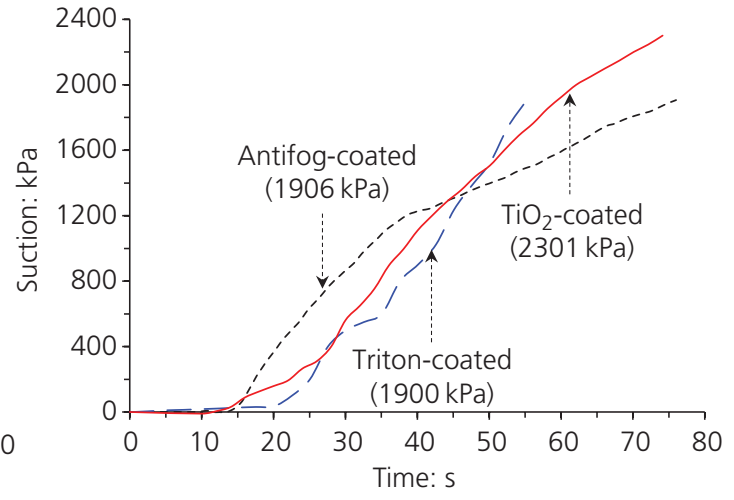

(b)

Figure 10. Free evaporation tests: (a) HCTs with mechanically polished diaphragms and (b) HCTs with hydrophilic-coated diaphragms values in parentheses indicate the $s_{\max }$

of free evaporation (FE) tests carried out on WT1, WT4, WT5, WT8, WT10 and WT11. As was expected, the tensiometer with FM diaphragm (WT1) cavitated at approximately 65\% (-972 kPa) of its nominal capacity. A plausible explanation for cavitation mechanism in this case could be the development of air cavities in the reservoir due to the presence of a large number of gas nuclei entrapped in the crevices of the water reservoir walls. Tensiometers WT4 (SP-polished diaphragm) and WT5 (DP-polished diaphragm) cavitated, respectively, at 1809 and $1838 \mathrm{kPa}$ suctions, values of up to $122 \%$ of the nominal capacity. Comparing these results with the performance of WT1 (FM diaphragm) validates the significance of having a smooth surface on the interior walls of the water reservoir to improve cavitation resistance and, hence, $s_{\max }$. As explained earlier, typically, the air cavities are initially formed in the ceramic disc. However, the development of air cavities in the water reservoir, in a faster rate than in the ceramic disc, is also contingent. It is hard, however, to comment on the predominant mechanism of cavitation for WT4 (SP diaphragm) and WT5 (DP diaphragm), as the free air bubbles may have been initially formed in the water reservoir. Finally, the response of the tensiometers with the AF-, Triton- and titanium dioxide-coated diaphragms showed greater resistance against cavitation when compared with other prototypes. These HCTs sustained suctions of 1906, 1900 and $2301 \mathrm{kPa}$, respectively. Identifying the contribution of diaphragms' surface smoothness in increasing the $s_{\max }$ might still be premature when comparing the performance of the sensors with the AF-coated diaphragm, WT8, and the Triton-coated diaphragm, WT10 ( $s_{\max }$ values of up to $127 \%$ of the nominal capacity), with the performance of the polished-diaphragm HCTs. However, the role of the water reservoir surface roughness is clearer when under identical initial conditions (i.e. the degree of saturation of the ceramic discs); an $s_{\max }$ value of $153 \%$ of the nominal capacity was recorded by the HCT with titanium dioxide-coated diaphragm (WT11).

\section{Response to sudden pressure changes}

Cyclic evaporation (CE) tests were performed on the tensiometers to evaluate the sensors' capability in recording sudden changes in suction, as suggested by Guan and Fredlund (1997), He et al. (2006) and Mancuso and Papa (2014). The probes were subjected to cycles of free evaporation up to predetermined suctions and subsequently placed in contact with free water after each evaporation cycle and allowed for pressure recovery to atmospheric pressure. Figure 11(a) shows the results of CE tests on WT1 (FM diaphragm). WT1 was cavitated at $976 \mathrm{kPa}$ and after ten evaporation cycles. It was observed that the HCTs with polished diaphragms exhibited relatively similar performances during CE tests (Figures 11(b) and 11(c)). However, they recorded significantly lower values (about $300 \mathrm{kPa}$ ) of $s_{\max }$ during $\mathrm{CE}$ tests than the FE tests. Similar results were obtained from HCTs with AF- and titanium dioxide-coated diaphragms (Figures 11(d) and 11(f)). The HCT with the Triton-coated diaphragm (WT10) was, however, able to sustain a suction value very close to its observed $s_{\max }$ in the FE test (Figure 11(e)). A possible explanation for the underlying mechanism of cavitation during CE tests is that by applying cycles of negative pressure initially, microbubbles develop on the reservoir walls; subsequently, with increasing the number of cycles, the density of the microbubbles decreases (Bremond et al., 2005), resulting in their detachment from the surface, forming free air cavities and, hence, facilitating cavitation at lower suctions than $s_{\max }$. Except WT1 (FM diaphragm), the other HCTs were cavitated at suctions above their nominal capacity. The presence of a fewer number of crevices on the reservoir walls results in the delayed interfusion of detached microbubbles into larger free air bubbles capable of forming discontinuities in the water reservoir. Furthermore, for HCTs with coated diaphragms, an additional tensile force is required to overcome the attractive forces exerted by the hydrophilic surfaces to the water molecules at the air-water interfaces of entrapped microbubbles, resulting in the elevation of cavitation threshold.

Another noteworthy observation was that after each cycle of cavitation to prespecified suctions, and upon placing the tensiometer in free water, the measurements did not return to zero value even if enough time was given for pressure equilibrium. After each cycle of cavitation, the sensors measured a small negative pressure, which was increased with increasing the number of cavitation cycles. A 
Cavitation in high-capacity tensiometers:

effect of water reservoir surface

roughness

Bagheri, Rezania and Mousavi Nezhad

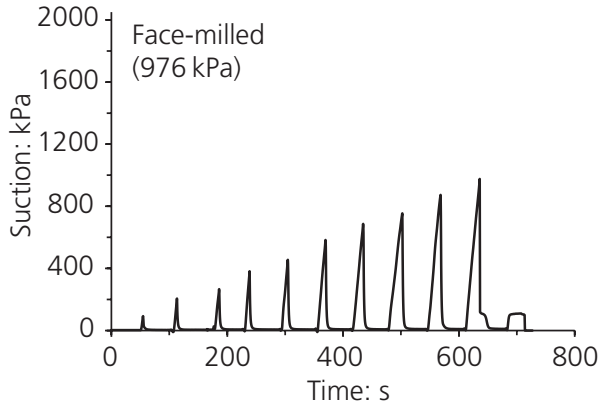

(a)

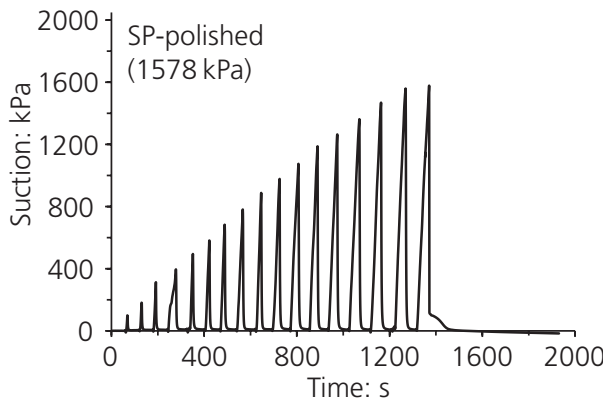

(b)

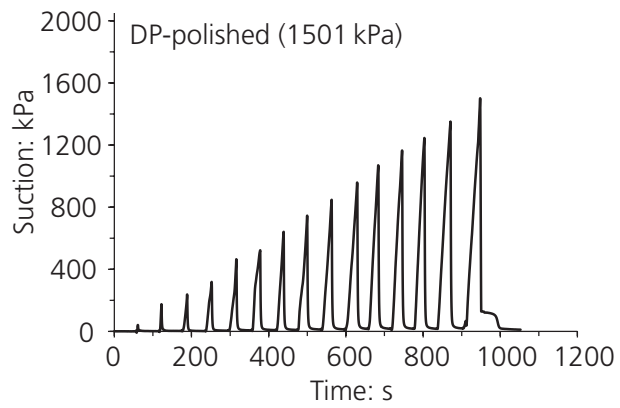

(c)

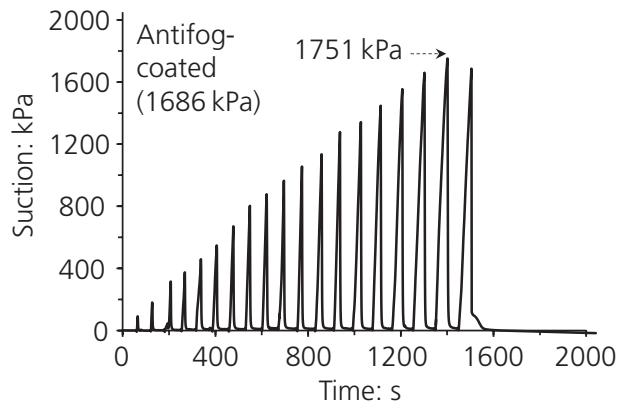

(d)

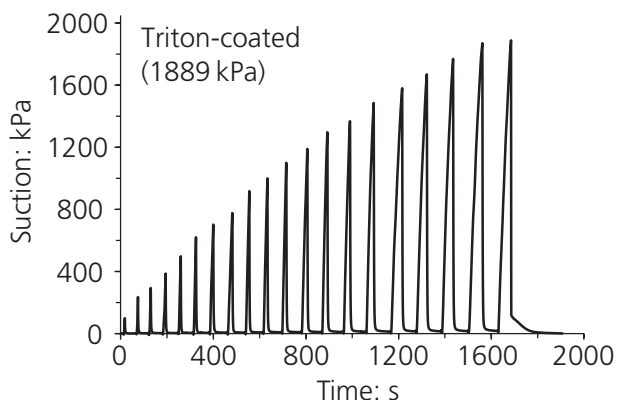

(e)

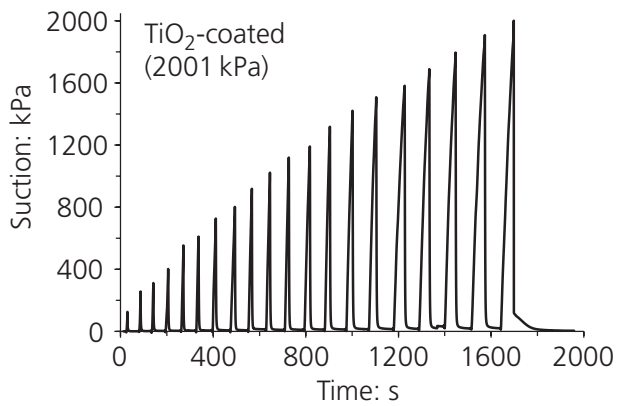

(f)

Figure 11. Cyclic evaporation tests - values in parentheses indicate the $s_{\max }$

possible explanation for this observation could be the development and enlargement of air cavities in the ceramic disc that prevent pressure equalisation between the water in the reservoir, which is under tension, and the free water at atmospheric pressure.

\section{Evaluation of long-term stability of measurements and $t_{\max }$}

As mentioned earlier, one drawback of the HCTs is their inability to measure high suctions $(>1 \mathrm{MPa})$ for long periods of time. To investigate the effectiveness of the proposed diaphragm-treatment methods for improving the long-term performance of the new HCTs, two sets of experiments - namely, constant suction tests and increasing suction tests - were carried out on reconstituted London Clay (LC) specimens prepared from one-dimensional consolidation of soil slurry. In constant suction tests, HCT measurements were carried out on soil samples air-dried to water contents corresponding approximately to suctions of 600 and $1000 \mathrm{kPa}$, based on the information obtained from the soil water retention curve. In increasing suction tests, HCT measurements were carried out on initially saturated specimens, which were exposed to the atmosphere and allowed to lose moisture at a relatively constant rate. Both sets of experiments were performed in a new unsaturated oedometer cell (Figure 12). The cell accommodates a 75 dia. mm cylindrical specimen that is $20 \mathrm{~mm}$ high. The special design of the loading cap allows for the installation of two HCTs on the specimen. A transparent nitrile membrane was used to seal the annular gap between the cell body and the loading cap. Prior to the experiments, the ultimate contact between the tensiometer ceramic disc and the specimen was ensured by covering the ceramic disc with some soil paste. The weight of the loading cap also contributes in providing ultimate contact between the HCT and the specimen. All experiments were conducted in a temperature- and humidity-controlled environment.

\section{Constant suction tests}

Table 4 presents details of the long-term suction measurements on constant suction specimens. The equilibrium suction $\left(s_{\mathrm{eq}}\right)$ was determined when pressure changes were in the range of $\pm 0 \cdot 4 \mathrm{kPa}$. 

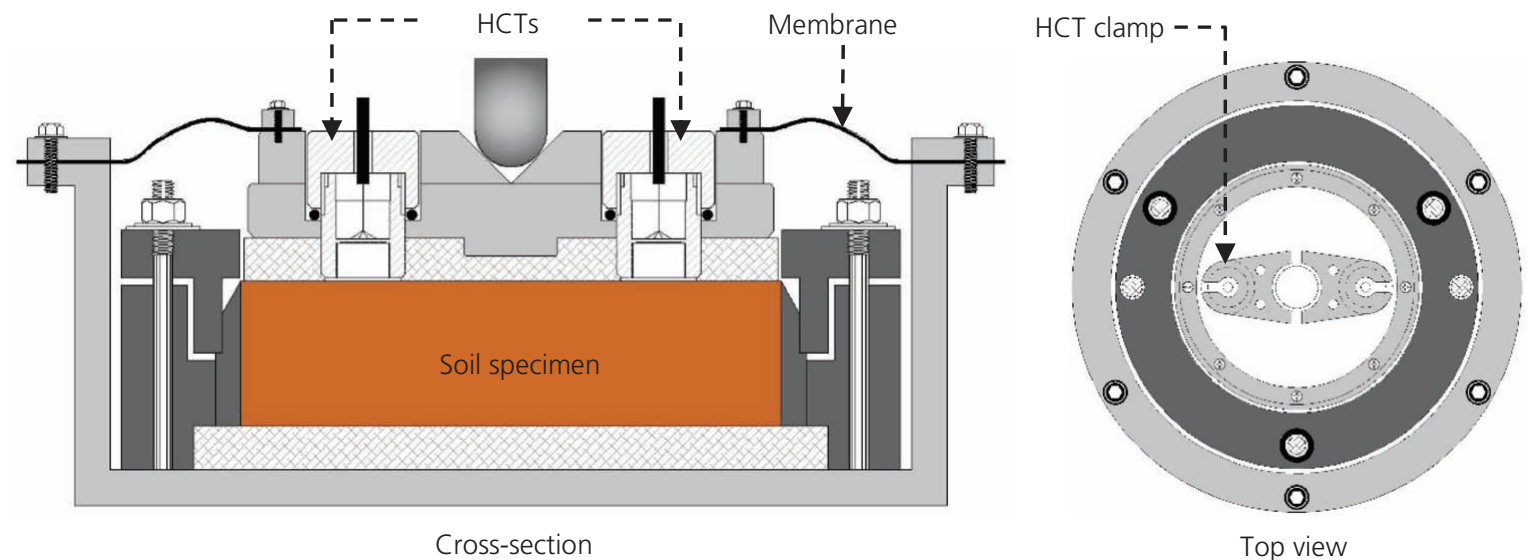

Figure 12. A new oedometer cell for testing unsaturated soil specimens

Table 4. Long-term suction measurement tests

\begin{tabular}{|lcclc|} 
Test number & Cell number & $\boldsymbol{s}_{\mathbf{e q}}: \mathbf{k P a}$ & $\mathbf{H C T}$ & Duration: $\mathbf{h}^{\mathbf{a}}$ \\
\hline 1 & A & 579 & WT1 & 38 \\
2 & A & 582 & WT4 & 303 \\
3 & B & 570 & WT5 & 309 \\
4 & B & 575 & WT8 & 300 \\
5 & C & 606 & WT10 & 412 \\
6 & C & 608 & WT11 & 529 \\
7 & A & 973 & WT1 & 1 \\
8 & A & 977 & WT4 & 268 \\
9 & B & 971 & WT5 & 262 \\
10 & B & 968 & WT8 & 267 \\
11 & C & 991 & WT10 & 360 \\
12 & C & 996 & WT11 & 475 \\
\hline
\end{tabular}

${ }^{a}$ Includes the pressure equilibrium duration

Figures 13(a) and 13(b) present the results of long-term suction measurements on specimens having approximately $600 \mathrm{kPa}$ suction. WT1 (FM diaphragm) was able to sustain a suction of $579 \mathrm{kPa}$ for a duration of only $38 \mathrm{~h}$, at which it was cavitated. For this sensor, the possible mechanism of cavitation appears to be controlled by the development of air cavities at the diaphragm-water interface. The HCTs with polished diaphragms (WT4 and WT5) exhibited an improved performance and were able to sustain suctions of 582 and $570 \mathrm{kPa}$ for durations of 303 and $309 \mathrm{~h}$, respectively. For these two sensors, the mechanism of cavitation is unknown. However, minimising the presence of air bubbles in the water reservoir almost certainly played a significant role in prolonging the measurement durations, even if cavitation was first initiated in the water reservoir. The performance of the AF-coated diaphragm (WT8) was also very similar to the polished-diaphragm HCTs, indicating the possibility of dissolution of the AF coating during the continuous use of this sensor and the application of cycles of cavitation and pressurisation. This tensiometer measured a suction of $575 \mathrm{kPa}$ for a duration of $300 \mathrm{~h}$. It must be mentioned here that after about $40 \mathrm{~h}$ of measuring constant suctions, WT4 (SP diaphragm), WT5 (DP diaphragm) and WT8 (AF-coated diaphragm) recorded an increasing rate of suction up to their tension breakdown. This could be due to leakage from the sealing membrane of oedometer cells $\mathrm{A}$ and $\mathrm{B}$. The recorded pressure differences were, however, within the range $10-15 \mathrm{kPa}$, which is small enough not to have any significant impacts on the test results. The WT10 (Triton-coated diaphragm) and WT11 (titanium dioxide-coated diaphragm) tensiometers exhibited significantly improved performances with $t_{\max }$ of 412 and $529 \mathrm{~h}$, corresponding to 606 and $608 \mathrm{kPa}$ suctions, respectively. This notably improved performance was believed to be due to $(a)$ the minimised number of nucleation sites in the water reservoir and $(b)$ the strong affinity of water molecules to the hydrophilic surfaces of the reservoir walls, which require higher tension and/or sustained tension duration to cause cavitation.

The performances of WTs in contact with specimens having approximately $1000 \mathrm{kPa}$ suction are shown in Figures 13(c) and 13(d). WT1 (FM diaphragm) cavitated after only $1 \mathrm{~h}$ and before reaching equilibrium with the specimen's pore water tension. The pressure equilibrium between the HCT and the specimen is typically achieved in about $10 \mathrm{~min}$ (Wijaya and Leong, 2016); in this case, the delayed apparent equilibrium was believed to be due to high water content in the soil paste applied to the ceramic disc of the HCTs. WT4 (SP diaphragm) and WT5 (DP diaphragm) were able to record suctions of 977 and $971 \mathrm{kPa}$ for a time period of 268 and $262 \mathrm{~h}$, respectively. Once again, the performance of WT8 (AF-coated diaphragm) was found to be very similar to the polished-diaphragm HCTs. Finally, WT10 (Triton-coated diaphragm) and WT11 (titanium dioxide-coated diaphragm) showed remarkable records of measuring suctions of 991 and $996 \mathrm{kPa}$ for durations of 360 and $475 \mathrm{~h}$, respectively. Under higher suctions, the expansion of air cavities at the diaphragm-water interface and inside the ceramic disc was accelerated, leading to lower $t_{\max }$ values. Considering $t_{\max }$ values obtained from WT4 (SP diaphragm) as the reference, the improvements achieved from Triton- and titanium dioxide-coating methods were in the range $134-177 \%$ for both sets of experiments carried out. 

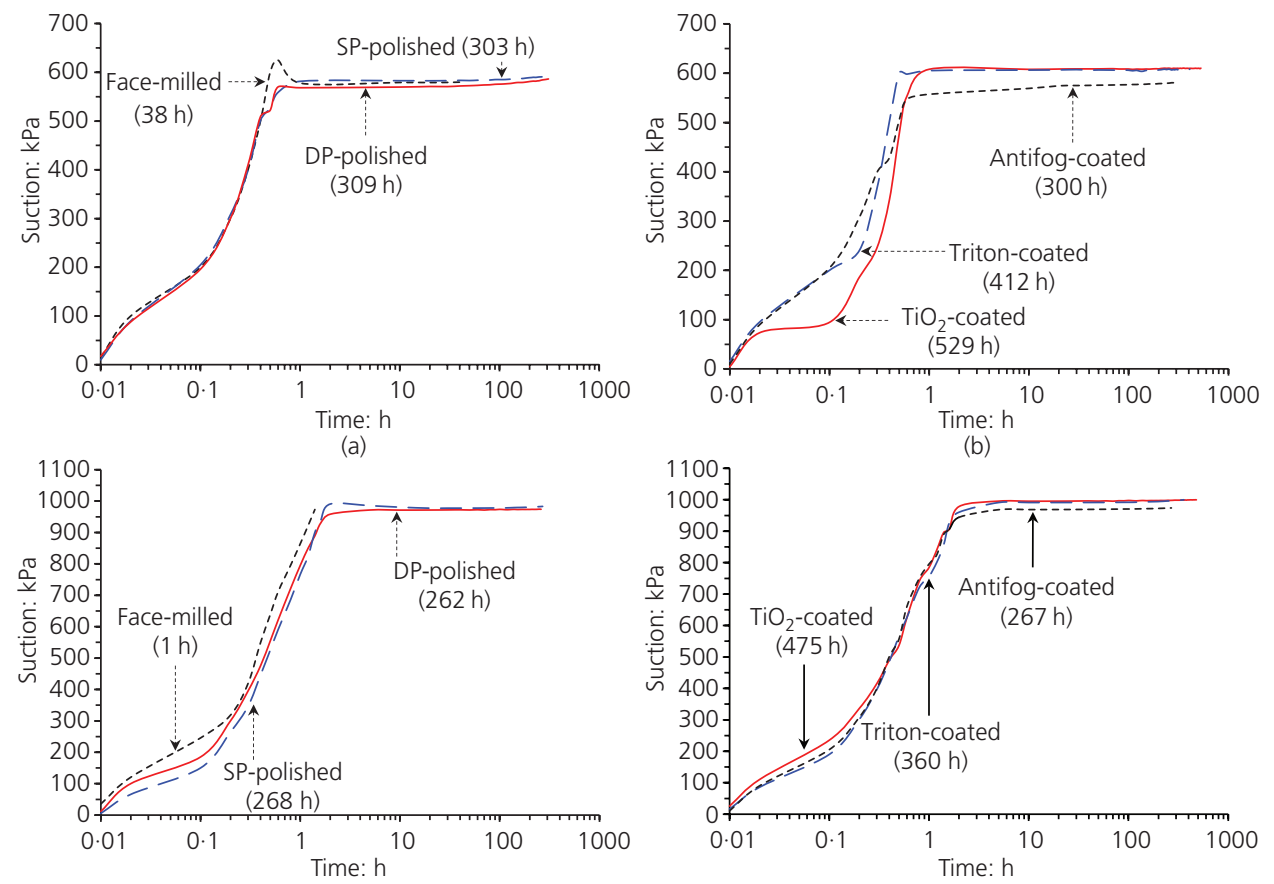

(c)

(d)

Figure 13. Long-term performance of the HCTs during constant suction tests: (a) mechanically polished diaphragms under $\sim 600 \mathrm{kPa}$ suction; (b) hydrophilic-coated diaphragms under $\sim 600 \mathrm{kPa}$ suction; (c) mechanically polished diaphragms under $\sim 1000 \mathrm{kPa}$ suction; (d) hydrophilic-coated diaphragms under $\sim 1000 \mathrm{kPa}$ suction - values in parentheses indicate the $t_{\max }$

The HCTs with hydrophilic-coated diaphragms were also used in long-term consolidation tests on LC specimens having suctions of around $200 \mathrm{kPa}$. The HCTs were able to measure the constant suction of $200 \mathrm{kPa}$ for a duration of $37 \mathrm{~d}$ without being cavitated. At the end of the tests, free evaporation tests were carried out on the tensiometers (Figure 14). As seen in the figure, the HCTs were able to record higher $s_{\max }$ values than those obtained prior to the

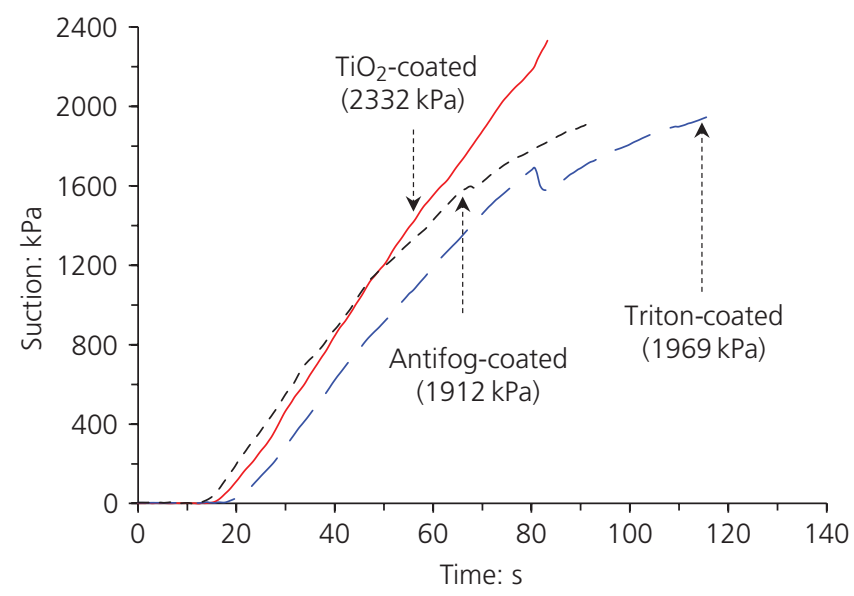

Figure 14. Free evaporation tests on HCTs with hydrophilic-coated diaphragms after long-term consolidation tests - values in parentheses indicate the $s_{\max }$ long-term tests (shown in Figure 10(b)). This response could be attributed to pore clogging in the ceramic discs due to prolonged contact with a very fine-grained clayey soil that resulted in a decreased porosity of the ceramic disc and consequently increased its AEV. Based on these results, the development of gas bubbles in the ceramic filter can be considered as the possible predominant cavitation mechanism in the new HCTs.

\section{Increasing suction tests}

Figure 15 shows the recorded suction changes with time on continuously drying specimens. As expected, WT1 (FM diaphragm) was only able to record the evolution of suction for $18 \mathrm{~h}$ and cavitated at $954 \mathrm{kPa}$. It is more likely that cavitation was first initiated in the water reservoir with the rough surface, rather than in the ceramic disc, although a definite conclusion cannot be drawn. Comparing the performance of this sensor with WT4 and WT5 that had polished diaphragms and cavitated at suctions of 1610 and $1672 \mathrm{kPa}$, after 24 and $27 \mathrm{~h}$, respectively, confirms the important role of the diaphragm surface smoothness in improving the cavitation threshold and delaying its occurrence. WT8 (AF-coated diaphragm) showed very similar performance to WT5, with $s_{\max }=1693 \mathrm{kPa}$ and $t_{\max }=28 \mathrm{~h}$, further recognising the likelihood of the $\mathrm{AF}$ microlayer dissolution into the water during the long-term use of the HCT. WT10 (Triton-coated diaphragm) cavitated at $1763 \mathrm{kPa}$ and after $32 \mathrm{~h}$, whereas WT11 (titanium dioxide-coated diaphragm) recorded a tension breakdown of $2104 \mathrm{kPa}$ after $28 \mathrm{~h}$ of continuous measurement of increasing 


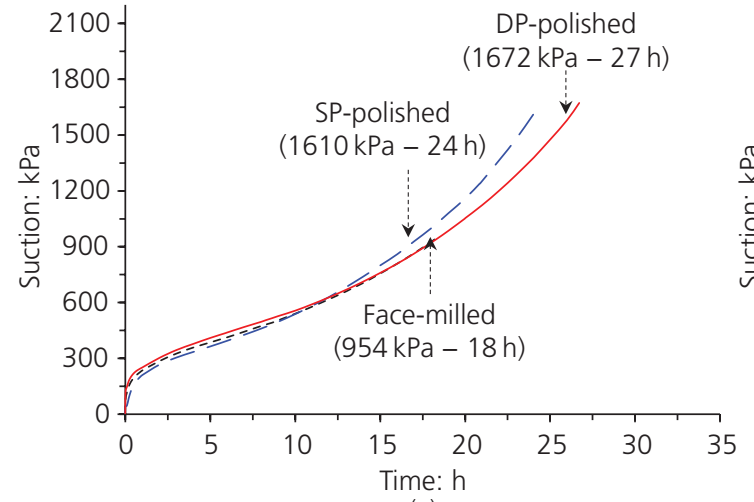

(a)

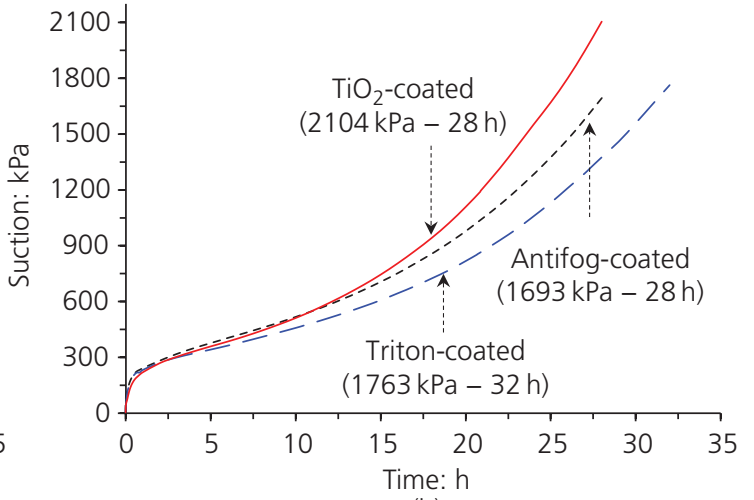

(b)

Figure 15. Long-term performance of the HCTs during increasing suction tests - values in parentheses indicate the $s_{\max }$ and $t_{\max }$, respectively

suction. The significant differences in $s_{\max }$ and $t_{\max }$ values recorded by WT10 and WT11 placed on the same specimen may be attributed to the possible differences in evaporation rate at the contact area of the two HCTs and the specimen. A possible reason for the lower $s_{\max }$ values observed in this set of experiments can be due to the effect of air diffusion into the ceramic filter during the course of air drying, facilitating cavitation in HCTs.

\section{Conclusions}

In this study, the effect of surface roughness of the water reservoir walls on the performance of a newly designed HCT was examined. From the findings, the following conclusions can be drawn.

- The mechanism of cavitation in tensiometers is indeed influenced by the surface roughness of the water reservoir. Smoother and more water-attractive surfaces in the water reservoir can significantly reduce the number of entrapped gas bubbles and nucleation sites, hence increasing the cavitation threshold in HCTs.

- While the HCT with FM diaphragm was only capable of measuring suctions up to $65 \%$ of its nominal capacity, the surface-polishing techniques resulted in an increase of $s_{\max }$ values of up to $122 \%$ of the nominal capacity. Furthermore, $\mathrm{AF}$ and Triton coatings and titanium dioxide coating increased the $s_{\max }$ to 127 and $153 \%$ of the nominal capacity, respectively.

Considering the $t_{\max }$ values obtained from the SP-polished $\mathrm{HCT}$ as the reference, the improvements achieved from Triton- and titanium dioxide-coating methods were in the range of $134-177 \%$

- The mechanical surface-polishing methods reduce the hydrophilicity of the diaphragms and may hence offset the improvement achieved by reducing the surface roughness. This effect is more highlighted during long-term measurements of constant high suctions.

- The titanium dioxide hydrophilic coating appears to be promising in improving the $s_{\max }$ and $t_{\max }$ values of the HCTs. Its strong bonding properties to the substrate also counterbalances for potential issues caused by the dissolution or detachment of the coating layer and, hence, guarantees the long-term functionality of the HCT.

- Further works are to be done for the evaluation of the longterm stability and adhesion of hydrophilic coatings to the diaphragms of the HCTs.

\section{Acknowledgements}

The authors are grateful to Professor Alessandro Tarantino of the University of Strathclyde for valuable advices in the design of the new HCT and to Mr Graeme Thacker of the engineering workshop at the University of Warwick for his useful suggestions in the design and manufacturing of the presented instrument. Thanks are also given to Dr Sina Saremi Yarahmadi of Loughborough University for his support in contact angle measurements and the selection of coating materials.

\section{REFERENCES}

Bremond N, Arora M, OhI CD and Lohse D (2005) Cavitation on surfaces Journal of Physics: Condensed Matter 17(45): S3603-S3608, https:// doi.org/10.1088/0953-8984/17/45/054.

Chevallier P, Turgeon S, Sarra-bournet C, Turcotte R and Laroche G (2011) Characterization of multilayer anti-fog coatings. Applied Materials \& Interfaces 3(3): 750-758, https://doi.org/10.1021/ am1010964.

Chiu CF, Cui YF, Delage P, De Laure E and Haza E (2005) Lessons learnt from suction monitoring during centrifuge modelling. In Advanced Experimental Unsaturated Soil Mechanics: Proceedings of the International Symposium on Advanced Experimental Unsaturated Soil Mechanics (Tarantino A, Romero E and Cui YJ (eds)). Balkema, Leiden, the Netherlands, pp. 3-8.

Conradi M and Kocijan A (2016) Surface and anticorrosion properties of hydrophobic and hydrophilic $\mathrm{TiO}_{2}$ coatings on a stainless-steel substrate. Materials and Technology 50(6): 967-970, https://doi.org/ 10.17222/mit.2016.068.

Cui YJ, Tang AM, Mantho AT and De Laure E (2008) Monitoring field soil suction using a miniature tensiometer. Geotechnical Testing Journal 31(1): 95-100, https://doi.org/10.1520/GTJ100769.

Cunningham MR, Ridley AM, Dineen K and Burland JB (2003) The mechanical behaviour of a reconstituted unsaturated silty clay. Géotechnique 53(2): 183-194, https://doi.org/10.1680/geot.2003.53.2. 183. 
Drelich J, Chibowski E, Meng DD and Terpilowski K (2011) Hydrophilic and superhydrophilic surfaces and materials. Soft Matter 7(21): 9804-9828, https://doi.org/10.1039/c1sm05849e.

Guan Y and Fredlund DG (1997) Use of tensile strength of water for the direct measurement of high soil suction. Canadian Geotechnical Journal 34(4): 604-614, https://doi.org/10.1139/t97-014.

Hasegawa M, Seireg A and Lindberg RA (1976) Surface roughness model forturning. Tribology International 9(6): 285-289, https://doi.org/ 10.1016/0301-679X(76)90019-0.

He L, Leong EC and Algamal A (2006) A miniature tensiometer for measurement of high matrix suction. ASCE Geotechnical Special Publication 147(2): 1897-1907, https://doi.org/10.1061/40802(189)160.

Henderson SJ and Speedy RJ (1980) A Berthelot-Bourdoon tube method for studying water under tension. Journal of Physics E: Scientific Instrumentation 13(7): 778-782, https://doi.org/10.1088/0022-3735/ $13 / 7 / 019$.

ISO (International Organization for Standardization) (1987) ISO/DIS 4287-1: Surface roughness terminology. Part 1: surface and its parameters. ISO, Geneva, Switzerland.

Jones SF, Evans GM and Galvin KP (1999) Bubble nucleation from gas cavities - a review. Advances in Colloid and Interface Science 80(1): 27-50, https://doi.org/10.1016/S0001-8686(98)00074-8.

Jotisankasa A, Porlila W, Soralump S and Mairiang W (2007) Development of a low-cost miniature tensiometer and its applications. In Proceedings of 3rd Asian Conference on Unsaturated Soils UNSATASIA 2007 (Yin ZZ, Yuan YP and Chiu ACF (eds)). Science Press, Nanjing, China, pp. 475-480.

Li L and Zhang X (2014) Development of a new high-suction tensiometer. In Soil Behavior and Geomechanics: Selected Papers from the Proceedings of the 2014 GeoShanghai International Congress (Zhang $\mathrm{X}$, Chu J and Bulut R (eds)). American Society of Civil Engineers, Reston, VA, USA, Geotechnical Special Publication no. 236, pp. 416-425.

Lourenço SDN (2008) Suction Measurement and Water Retention in Unsaturated Soils. PhD thesis, Durham University, Durham, UK.

Lourenço SDN, Gallipoli D, Toll DG and Evans FD (2006) Development of a commercial tensiometer for triaxial testing of unsaturated soils. In Unsaturated Soils 2006 (Miller GA, Zapata CE, Houston SL and Fredlund DG (eds)). American Society of Civil Engineers, Reston, VA, USA, Geotechnical Special Publication no. 147, pp. 1875-1886.

Lourenço SDN, Gallipoli D, Toll DG et al. (2008) Calibrations of a high suction tensiometer. Géotechnique 58(8): 659-668, https://doi.org/ 10.1680/geot.2008.58.8.659.

Lourenço SDN, Gallipoli D, Toll DG and Augarde CE (2012) Cavitation in high suction tensiometers: effect of temperature, time of use, and stone drying. In Unsaturated Soils: Theory and Practice: Proceedings of the 5th Asia-Pacific Conference on Unsaturated Soils (Jotisankasa A (ed.)). Curran Associates, Red Hook, USA, pp. 385-391.

Mahler CF and Diene AA (2007) Tensiometer development for high suction analysis in laboratory lysimeters. In Experimental Unsaturated Soil Mechanics (Schanz T (ed.)). Springer Science \& Business Media, Berlin, Germany, vol. 112, pp. 103-115.

Mahler CF, Pacheco AC and Souza HG (2002) Development of an automatic tensiometer in laboratory using a Mini-Lysimeter. In Unsaturated Soils: Proceedings of the Third International Conference, UNSAT 2002 (Juca JFT, de Campos TMP and Marinho FAM (eds)). Balkema, Lisse, the Netherlands, vol. 3, pp. 1021-1027.

Mancuso C and Papa R (2014) A high capacity tensiometer to measure soil suction. Proceedings of 20th IMEKO TC4 International Symposium: Measurement of Electrical Quantities, Benevento, Italy, pp. 212-215.

Mantho AT (2005) Soil-Atmosphere Transfers - Application to Drought. $\mathrm{PhD}$ thesis, Ecole National des Ponts et Chaussrees, Champs-surMarne, France.
Marinho FAM and Chandler RJ (1994) Discussion: a new instrument for the measurement of soil moisture suction. Géotechnique 44(3): 551-556, https://doi.org/10.1680/geot.1994.44.3.551.

Marinho FAM, Take WA and Tarantino A (2008) Measurement of matric suction using tensiometric and axis translation techniques. Geotechnical and Geological Engineering 26(6): 615-631, https://doi. org/10.1007/s10706-008-9201-8.

Marinho FAM and Pinto CS (1997) Soil suction measurement using a tensiometer. Symposium on Recent Development in Soil and Pavement Mechanics, Rio de Janeiro, Brazil, pp. 249-254.

Meilani I, Rahardjo H, Leong EC and Fredlund DG (2002) Mini suction probe for matric suction measurements. Canadian Geotechnical Journal 39(6): 1427-1432, https://doi.org/10.1139/t02-101.

Mendes J and Buzzi O (2013) New insight into cavitation mechanisms in high-capacity tensiometers based on highspeed photography. Canadian Geotechnical Journal 50(5): 550-556, https://doi.org/10. 1139/cgj-2012-0393.

Mendes J, Gallipoli D, Toll D, Augarde CE and Evans FD (2008) A system for field measurement of suctions using high capacity tensiometers. In Unsaturated Soils. Advances in Geo-Engineering: Proceedings of the 1st European Conference, E-UNSAT 2008 (Toll DG, Augarde CE, Gallipoli D and Wheeler SJ (eds)). CRC Press, Boca Raton, FL, USA, pp. 219-225.

Mendes J, Gallipoli D, Boeck F, von Unold G and Tarantino A (2016) Building the UPPA high capacity tensiometer. In Proceedings of the $3 r d$ European Conference on Unsaturated Soils E-UNSAT2016 (Delage P, Cui YJ, Pereira JM and Tang AM (eds)). EDP Sciences, Paris, France, pp. 426-431.

Ohkoa Y, Saitohb S, Tatsumaa T and Fujishimaa A (2001) Photoelectrochemical anticorrosion and self-cleaning effects of a $\mathrm{TiO}_{2}$ coating for type 304 stainless steel. Journal of Electrochemical Society 148(1): B24-B28, https://doi.org/10.1149/1.1339030.

Ridley AM (1993) The Measurement of Soil Moisture Suction. PhD thesis, University of London, London, UK.

Ridley AM and Burland JB (1993) A new instrument for the measurement of soil moisture suction. Géotechnique 43(2): 321-324, https://doi.org/ 10.1680/geot.1993.43.2.321.

Ridley AM and Burland JB (1995) Measurement of suction in materials which swell. Applied Mechanics Reviews 48(10): 727-732, https://doi. org/10.1115/1.3005055.

Ridley AM and Burland JB (1996) A pore pressure probe for the in situ measurement of soil suction. In Advances in Site Investigation Practice. Thomas Telford, London, UK, pp. 510-520.

Ridley AM and Burland JB (1999) Discussion: Use of tensile strength of water for the direct measurement of high soil suction. Canadian Geotechnical Journal 36(1): 178-180, https://doi.org/10.1139/t98-080.

Ridley AM, Dineen K, Burland JB and Vaughan PR (2003) Soil matrix suction: some examples of its measurement and application in geotechnical engineering. Géotechnique 53(2): 241-253, https://doi. org/10.1680/geot.2003.53.2.241.

Rojas JC, Pagano L, Zingariello C et al. (2008) A new high capacity tensiometer: first results. In Unsaturated Soils. Advances in GeoEngineering: Proceedings of the 1st European Conference, E-UNSAT 2008 (Toll DG, Augarde CE, Gallipoli D and Wheeler SJ (eds)). CRC Press, Boca Raton, FL, USA, pp. 205-211.

She HY and Sleep BE (1998) The effect of temperature on capillary pressure-saturation relationships for air-water and perchloroethylenewater systems. Water Resources Research 34(10): 2587-2597, https:// doi.org/10.1029/98WR01199.

Sjoblom KJ (2000) The Mechanics Involved during the Desaturation Process of a Porous Matrix. PhD thesis, Massachusetts Institute of Technology, Cambridge, MA, USA.

Stannard DI (1992) Tensiometers-theory, construction and use. Geotechnical Testing Journal 15(1): 48-58, https://doi.org/10.1520/ GTJ10224J. 
Cavitation in high-capacity tensiometers:

effect of water reservoir surface

roughness

Bagheri, Rezania and Mousavi Nezhad
Take WA (2003) The influence of seasonal moisture cycles on clay slopes. $\mathrm{PhD}$ thesis, Cambridge University, Cambridge, UK.

Take WA and Bolton MD (2003) Tensiometer saturation and the reliable measurement of soil suction. Géotechnique 53(2): 159-172, https:// doi.org/10.1680/geot.2003.53.2.159.

Tarantino A (2002) Panel lecture: direct measurement of soil water tension. In Unsaturated Soils: Proceedings of the Third International Conference, UNSAT 2002 (Juca JFT, de Campos TMP and Marinho FAM (eds)). Balkema, Lisse, the Netherlands, vol. 3, pp. 1005-1017. Tarantino A and Mongiovi L (2002) Design and construction of a tensiometer for direct measurement of matric suction. In Unsaturated Soils: Proceedings of the Third International Conference, UNSAT 2002 (Juca JFT, de Campos TMP and Marinho FAM (eds)). Balkema, Lisse, the Netherlands, vol. 1, pp. 319-324.

Tarantino A, Gallipoli D, Jommi C et al. (2016) Advances in the monitoring of geo-structure subjected to climate loading. In Proceedings of the 3rd European Conference on Unsaturated Soils EUNSAT2016 (Delage P, Cui YJ, Pereira JM and Tang AM (eds)). EDP Sciences, Paris, France, pp. 71-81.

Toker NK, Germaine JT, Sjoblom KJ and Culligan PJ (2004) A new technique for rapid measurement of continuous soil moisture characteristic curves. Géotechnique 54(3): 179-186, https://doi.org/10. 1680/geot.2004.54.3.179.
Toll DG, Lourenço SDN, Mendes J et al. (2011) Soil suction monitoring for landslides and slopes. Quarterly Journal of Engineering Geology and Hydrogeology 44(1): 23-33, https://doi.org/10.1144/1470-9236/09010.

Tsai FC, Yan BH, Kuan CY and Huang FY (2008) A Taguchi and experimental investigation into the optimal processing conditions for the abrasive jet polishing of SKD61 mold steel. International Journal of Machine Tools \& Manufacture 48(7): 932-945, https://doi.org/10. 1016/j.ijmachtools.2007.08.019.

Wang Z, Luan Y, Pang T and Liu W (1998) Elastic and electrolytic ultraprecision polishing. Metal Finishing 96(7): 22-24, https://doi.org/ 10.1016/S0026-0576(98)80041-X.

Wijaya M and Leong EC (2016) Performance of high-capacity tensiometer in constant water content oedometer test. International Journal of GeoEngineering 7: article 13, https://doi.org/10.1186/s40703-016-0027-6.

Yin S and Shinmura T (2004) Vertical vibration-assisted magnetic abrasive finishing and deburring for magnesium alloy. International Journal of Machine Tools \& Manufacture 44(12-13): 1297-1303, https://doi.org/ 10.1016/j.ijmachtools.2004.04.023.

Yu JC, Ho W, Lin J, Yip H and Wong PK (2003) Photocatalytic activity, antibacterial effect, and photoinduced hydrophilicity of $\mathrm{TiO}_{2}$ films coated on a stainless steel substrate. Environmental Science \& Technology 37(10): 2296-2301, https://doi.org/10.1021/es0259483.

\section{How can you contribute?}

To discuss this paper, please submit up to 500 words to the editor at journals@ice.org.uk. Your contribution will be forwarded to the author(s) for a reply and, if considered appropriate by the editorial board, it will be published as a discussion in a future issue of the journal. 